\title{
Optimum Thickness of UHPFRC Overlay for Restoration of Normal Concrete Elements
}

\author{
Aysha Haroon $^{1,2}$, B. H. Abu Bakar,", \\ ${ }^{1}$ School of Civil Engineering, University Sains Malaysia, 14300 Nibong Tebal, Pulau Pinang, Malaysia \\ ${ }^{2}$ Faculty of Civil Engineering, University of Nizwa, Nizwa, Sultanate of Oman
}

Received July 28, 2021; Revised September 16, 2021; Accepted October 18, 2021

\begin{abstract}
Cite This Paper in the following Citation Styles
(a): [1] Aysha Haroon, B. H. Abu Bakar, "Optimum Thickness of UHPFRC Overlay for Restoration of Normal Concrete Elements," Civil Engineering and Architecture, Vol. 9, No. 7, pp. 2237-2248, 2021. DOI: 10.13189/cea.2021.090711.
\end{abstract}

(b): Aysha Haroon, B. H. Abu Bakar (2021). Optimum Thickness of UHPFRC Overlay for Restoration of Normal Concrete Elements. Civil Engineering and Architecture, 9(7), 2237-2248. DOI: 10.13189/cea.2021.090711.

Copyright $(2021$ by authors, all rights reserved. Authors agree that this article remains permanently open access under the terms of the Creative Commons Attribution License 4.0 International License

\begin{abstract}
Ultra high performance fiber reinforced concrete (UHPFRC) is a promising new concrete, especially in repair and restoration. It has been identified to exhibit good bonding and strengthening properties with the old concrete as an overlay repair material. But its usage has not been much pronounced due to its high-cost factor which overshadows its efficacy, because certain constituents of UHPFRC are not readily and easily available. Hence, optimal usage of this concrete for repair and rehabilitation can greatly be beneficial to the construction industry. Therefore, this study is involved in identifying the optimum thickness of UHPFRC as a repair overlay material for normal concrete elements, so that the self-weight of the material can be reduced to its minimum, and indirectly the impact of its price can be greatly reduced. With this intention, normal concrete elements were repaired with different thicknesses of UHPFRC overlay starting from $15 \mathrm{~mm}$ to $50 \mathrm{~mm}$. The repaired composite composed of normal concrete substrate and varying thickness of UHPFRC overlay were subjected to different property evaluations to identify the optimum thickness of UHPFRC overlay in compression, tension, and shear. The ideal thickness of the UHPFRC repair overlay was concluded based on its ability to restore the original strength of the old normal concrete. It was upshot that an overlay thickness of $20 \mathrm{~mm}$ is more than sufficient to repair and restore the normal concrete.
\end{abstract}

Keywords Restoration, UHPFRC, Overlay, Repair, Optimum Thickness

\section{Introduction}

Ultra High Performance Concrete (UHPC) is a group or family of materials exhibiting incredibly high compressive strength and durability. It is categorized as a cement-based concrete with compressive strength equal to or more than $150 \mathrm{MPa}[1,2], 5 \mathrm{MPa}$ in tensile strength, and $4 \mathrm{MPa}$ in first cracking strength, that belongs to the family of engineered cementitious composites - ECC [3]. UHPFRC is an advanced development of concrete with upgraded concrete materials [4]. The composite is made up of cement, silica fume, fine sand, fibers, superplasticizer (SP), and water which is known as ultra-high performance fiber reinforced cementitious composite (UHPFRCC) [5]. The concept of this type of concrete includes optimization of granular gradation constituents, including a high percentage of internal fiber reinforcement and less than 0.25 of water to cementitious (W/C) ratio [6]. Generally, UHPFRC is comprised of materials such as cement, silica fume, steel fiber, a replacement of coarse aggregate with finer material, and a low water binder ratio [7]. All these high performance concretes developed required costly materials and sophisticated technologies.

To overcome these weaknesses, UHPFRC was produced with common technology and ordinary raw materials. The addition of superplasticizers and fine mineral additives enabled UHPC to be produced at an extremely low water/binder ratio of 0.16 , excellent workability with max. UHPC was developed with an extraordinarily low water/binder ratio of 0.16 , good workability with a maximum slump of $268 \mathrm{~mm}$, and 
compressive strength of $175.8 \mathrm{MPa}$ at 90 days and 182.9 $\mathrm{MPa}$ at 365 days owing to the incorporation of superplasticizers with fine mineral additives [8]. The fibers added in the high performance concretes were one of the main reasons for extraordinary strength due to difficulty in de-bonding since fibers can arrest micro-cracks and bridge the cracks as well. Incidentally, a study was undertaken and identified that de-bonding and pulling out the fibers require more energy, and therefore toughness and resistance to cyclic and dynamic loading substantially increased. The tensile capacity of the UHPFRC fibers across cracks resulted in a high shear capacity in bending members, which increased the modulus of rupture, fracture toughness, and impact resistance. Following matrix cracking, randomly distributed short fibers in the matrix halted micro-cracks, bridged them, went through a pull-out process, and inhibited fracture propagation [9]. The fundamental behavior of ultra-high strength concrete beams reinforced with steel fibers was studied in which the steel rebar ratio was less than 0.02 and no coarse aggregate was utilized, and the results were employed to develop a model for predicting the flexural strength and deformation of ultra-high strength concrete beams in bending conditions [10]. The impact energy dissipation of UHPFRC was experimentally and analytically compared to conclude that hooked-ended steel fibers showed high impact strength, for a fiber volume fraction beyond $0.5 \%$ [11].

The current focus on the application of UHPFRC is in the field of repair and rehabilitation. Its uniqueness is more pronounced due to its extraordinary performance as a repair material. Rehabilitation or repairs involve the removal of deteriorated, damaged, or defective parts and carrying out an appropriate technique of repair procedures. Concrete rehabilitation is important and must be carried out promptly, especially in critical infrastructures. Repairs performed at an early stage would save expensive remediation. The application of UHPFRC as an overlay in rehabilitation considerably upgraded the structure response of the concrete member. This kind of concrete supplements the increasing strength of the composite concrete in terms of structural application. In addition, UHPFRC has excellent rheological properties which makes it easy to be handled on-site. Therefore, it will improve the serviceability and life cycle cost of rehabilitated concrete structures [12]. The load carrying capacity of conventional concrete beams is said to be enhanced with strain hardening fiber reinforced concrete, which didn't fail in shear mode [13]. The flexural capacity of concrete beams enhanced with a new concrete layer was investigated in an experimental setting, both on the tensile and compressive sides for different specimens. It was observed that the strengthening on compressive layer leads to monolithic behavior and when strengthened on the tensile side, an anchorage of the new layer and very good interface roughening is required and this was the most efficient method with a very high slip value [14]. The asphalt overlay for the steel bridge deck which was reported to have premature damage of the overlay was replaced with engineering cementitious composites - ECC overlay. The load-deflection response exhibited elastic, crack developing, and yield stages. The overlay thickness of ECC played an important role in its flexural behaviour enhancement [15].

Similarly, the mechanical and absorption characteristics of the junction between an ordinary concrete substrate and UHPFRC overlay have also been studied, which indicates that UHPFRC has good bonding with the normal concrete, which has shown enhanced behavior as a composite material [16]. Also, the feasibility of the usage of UHPFRC and a review of the previous works for rehabilitation using UHPFRC has been experimentally evidenced. He claims that when compared to other forms of concrete, UHPFRC has outstanding repair and retrofit capability in compressive and flexural strengthening, as well as strong bond strength and bond endurance. It has 250 times the ductility of regular concrete, resulting in exceptional performance and durability [17]. Also, the bond strength between normal concrete substrate and UHPFRC overlay was experimentally tested and discovered that UHPFC has excellent interlocking with the surface of $\mathrm{NC}$ substrate and provides bond strength larger than $\mathrm{NC}$ substrate. The sand-blasted surface between the old standard concrete base and its newer UHPFRC overlay produced improved results [18]. On the other hand, while the general features of UHPFRC imply acceptable compatibility in overlay applications, further work is required to determine the overall compatibility of the system. The bond integrity of UHPFRC to normal strength concrete (NSC) should be assessed to determine the strength of the composite system. Finally, the thickness of a UHPFRC overlay must be selected to lower the structure's dead load while retaining the bond interface's integrity [19]. If the repair is to endure all of the strains generated by forces such as volume changes, chemical and electrochemical effects, the repair material's compatibility with the current substrate is critical. The extraordinary mechanical and durability characteristics of UHPFRC make it an appropriate product designed to be used as a thin-bonded top layer on concrete beams and slabs to enhance the strength of the existing structure built with the normal concrete.

Even though UHPFRC has incomparable finest properties, it has not been much used in place of conventional concrete to date due to various reasons. Firstly, the production of UHPFRC involves materials very much different than that of normal concrete, which is not locally and easily available everywhere. Next, the procurement of materials imported from other places and the production of this concrete involves a higher budget compared to that of the normal concrete. Most importantly there are as such no defined mix design procedures or 
reference codes available, as existing for the conventional normal concrete. UHPFRC has qualities that are distinct from both high-performance concrete and ordinary concrete. UHPFRC has a compressive strength greater than $150 \mathrm{MPa}$ and it requires a high binder content, specific aggregates, and internal fiber reinforcing to assure non-brittle behavior. Cement, fine sand, quartz powder, silica fume, superplasticizer, low water to binder ratio, and the addition of either high strength steel fibers or non-metallic fibers are the primary components of UHPFRC [20].,

Also, one other main aspect for rare usage of UHPFRC is the impact of the higher cost compared to the cost of regular concrete. Since UHPFRC is so expensive, and its cost is comparatively high with normal concrete, its usage has been diminished in many applications. This particular factor has not been initiated for research to convince the usage of UHPFRC, even in the field of repair and rehabilitation, which creates a wider sense of emptiness to be addressed at this moment. Hence, it is required to identify ways to use UHPFRC in reduced quantities with higher efficiency. Therefore, to make the repair UHPFRC overlay generally applicable in the field of repair and rehabilitation as a cost-effective and competent repair material, an optimized thickness of the repair UHPFRC overlay for restoration and performance enhancement of normal concrete must also be determined.

\section{Materials and Methods}

This study encompasses the preparation of the composite for testing ensued in three phases. The first phase was to design, cast samples for characterization studies, and also cast the substrate samples of normal concrete. The second phase was to design and perform the characterization studies of the UHPFRC. The third phase was to deal with the surface preparation for the substrate normal concrete and overlay the UHPFRC onto the substrate normal concrete of varying thickness. Lastly, the composite samples were subjected to various tests to conclude at the optimum overlay thickness of UHPFRC, based on the original strength restoration of the normal concrete samples. The materials, production process, mixer machines of both the concretes were different, but the tests performed on plain normal concrete, plain UHPFRC, and the composite concrete were all same, to have an appraisal of the outcomes, concerning the strength gained after repair.

\subsection{Production and characterization studies of normal concrete samples}

This is the first phase of the study which involved the design and the casting of samples for characterization studies followed by the property evaluation of the normal concrete. Lastly, the normal concrete samples to be used as the substrate concrete were also cast in this phase.

\subsubsection{Materials and design mix of normal concrete}

The main emphasis of this study was on composites, in which the normal concrete was used as the substrate concrete, and hence the first step was to assess the basic mechanical characteristics of it. The normal concrete was made using OPC, natural river sand, water, and coarse aggregates of $10 \mathrm{~mm}$ and $20 \mathrm{~mm}$ yielding a concrete with a strength of 42 to $45 \mathrm{MPa}$ after 28 days and a slump of 30 to $60 \mathrm{~mm}$. The mix proportion of the normal concrete is presented in Table 1. The mixing of normal concrete was done using the conventional revolving drum mixer.

Table 1. Mix proportion of normal concrete

\begin{tabular}{|c|c|}
\hline Items & Quantity $\left(\mathbf{k g} / \mathbf{m}^{\mathbf{3}}\right)$ \\
\hline OPC (Type 1$)$ & 430 \\
\hline Coarse aggregate $(10 \mathrm{~mm})$ & 415 \\
\hline Coarse aggregate $(20 \mathrm{~mm})$ & 825 \\
\hline
\end{tabular}

\subsubsection{Characterization studies of normal concrete}

To carry out the characterization studies of the normal concrete, the compressive strength, the flexural strength, the slant shear strength, and the split tensile strength were assessed for the normal concrete at the ages of 3 days, 7 days, 14 days, 28 days and 1 year. Several cubes, cylinders, prisms, and beams were cast and subjected to only normal moist curing to evaluate its basic mechanical properties, conforming to ASTM standards.

\subsection{Production and characterization studies of UHPFRC}

The second stage of this study was to deal entirely with the repair material, UHPFRC. It deals with the designing of a mix, based on the workability and the target strength of $150 \mathrm{MPa}$. It should be noted that UHPFRC does not contain coarse aggregates and instead contains about 6.2 percent steel fibers, with fine aggregates accounting for around $41 \%$ of the total. The percentage of Portland cement in normal concrete is about $9 \%$ to $18 \%$ compared to $28.5 \%$ in UHPFRC. Normal concrete has a water content of 6 to $9 \%$, but UHPFRC has a water content of only 4.4 percent. This explains why UHPFRC has a water/cement ratio of roughly 0.2 , whereas regular concrete has a ratio of roughly 0.4 to 0.5 . Other essential extra components in UHPFRC help to bind all of the materials together and reduce the percentage of air voids. $1.2 \%$ superplasticizer aids in the bonding of the components. Silica flour and silica fume make the substance denser by reducing the number of air gaps. By volume, air spaces in normal concrete ranged from 2 to $6 \%$.

\subsubsection{Materials and design mix of UHPFRC}

The largest granular substance is mining sand, which ranges in size from 150 to $600 \mathrm{~m}$. Cement is the next 
biggest particle, with an average diameter of about $15 \mathrm{~m}$. Crushed silica powder, with an average diameter of $10 \mathrm{~m}$, is of similar size. The tiniest particle, silica fume, has a diameter small appropriate to fill the spaces between the cement and the crushed silica particles. Steel fiber reinforcement is the largest constituent in terms of size in the mix. The fibers in this investigation had a 37.5 aspect ratio (diameter $0.16 \mathrm{~mm}$, length $6 \mathrm{~mm}$ ) and tensile strength of $2850 \mathrm{MPa}$. The fibers were added into the mixture at a rate of $2 \%$ by volume (about $6 \%$ by weight), with a water/cement ratio of 0.2 . The mix composition of the UHPFRC, including the poly-carboxylate based superplasticizer, is provided in Table 2.

Table 2. Mix proportion of UHPFRC

\begin{tabular}{|c|c|}
\hline Materials & Quantity, $\left.\mathbf{( k g} / \mathbf{m}^{\mathbf{3}}\right)$ \\
\hline Cement & 788 \\
\hline Silica fume & 197 \\
\hline Silica Powder & 315 \\
\hline Fine aggregate & 866.80 \\
\hline Water & 197 \\
\hline Superplasticizer & 45 \\
\hline Steel Fiber & 157 \\
\hline w/c ratio & 0.2 \\
\hline
\end{tabular}

As can be seen in Table 3, the mix design of UHPFRC was based on the reference mixes available in the previous works of literature [16, 21-25] as well as different laboratory trials and errors. The ratios of silica fume to cement and silica powder (SP) to cement are 0.25 and 0.40 , respectively. Steel fibers at a cost-effective dosage of $2 \%$ by volume, or roughly $157 \mathrm{~kg} / \mathrm{m} 3$, are the most cost-effective. Sand is used as a filler, and a superplasticizer (SP) is added to the mix to make it more workable.

Table 3. Mix ratio of UHPFRC

\begin{tabular}{|c|c|c|c|c|c|c|}
\hline Cement & Sand & SF & SP & $\begin{array}{c}\text { W/C } \\
\text { ratio }\end{array}$ & SP & SF \\
\hline 1 & 1.1 & 0.25 & 0.40 & 0.22 & $\begin{array}{c}2 \% \text { of } \\
\text { binder } \\
\text { content }\end{array}$ & $\begin{array}{c}2 \% \text { of } \\
\text { concrete } \\
\text { volume }\end{array}$ \\
\hline
\end{tabular}

\subsubsection{Mixing \& Casting of UHPFRC}

The mixing of UHPFRC is entirely different from that of the normal concrete. All of the ingredients were weighed, and the UHPFRC was mixed using a planetary mixer machine with a $15 \mathrm{~kg}$ capacity, as indicated in Figure 1. The agitator RPMs for stir (slow), speed 1 (low), speed 2 (medium), and speed 3 (high) are 59, 107, 198, and 365 , respectively.

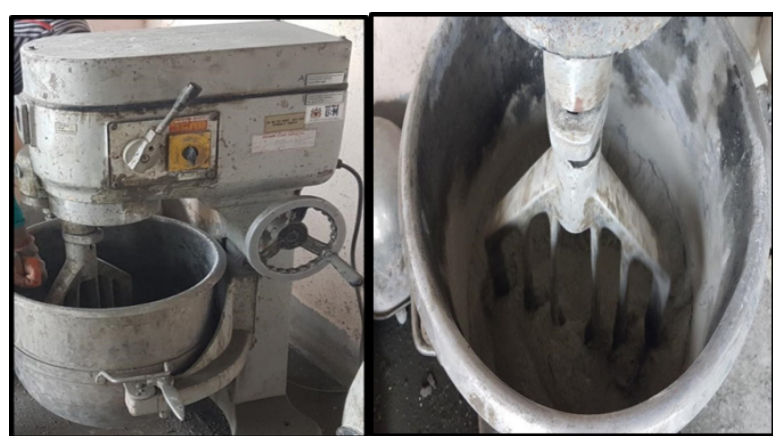

Figure 1. Planetary mixer machine used for mixing of UHPFRC

The mixing procedure is presented in Figure 2 and the mixing stages of UHPFRC of required consistency are illustrated in Figure 3. The casting of UHPFRC samples for characterization studies was similar to that of the normal concrete.

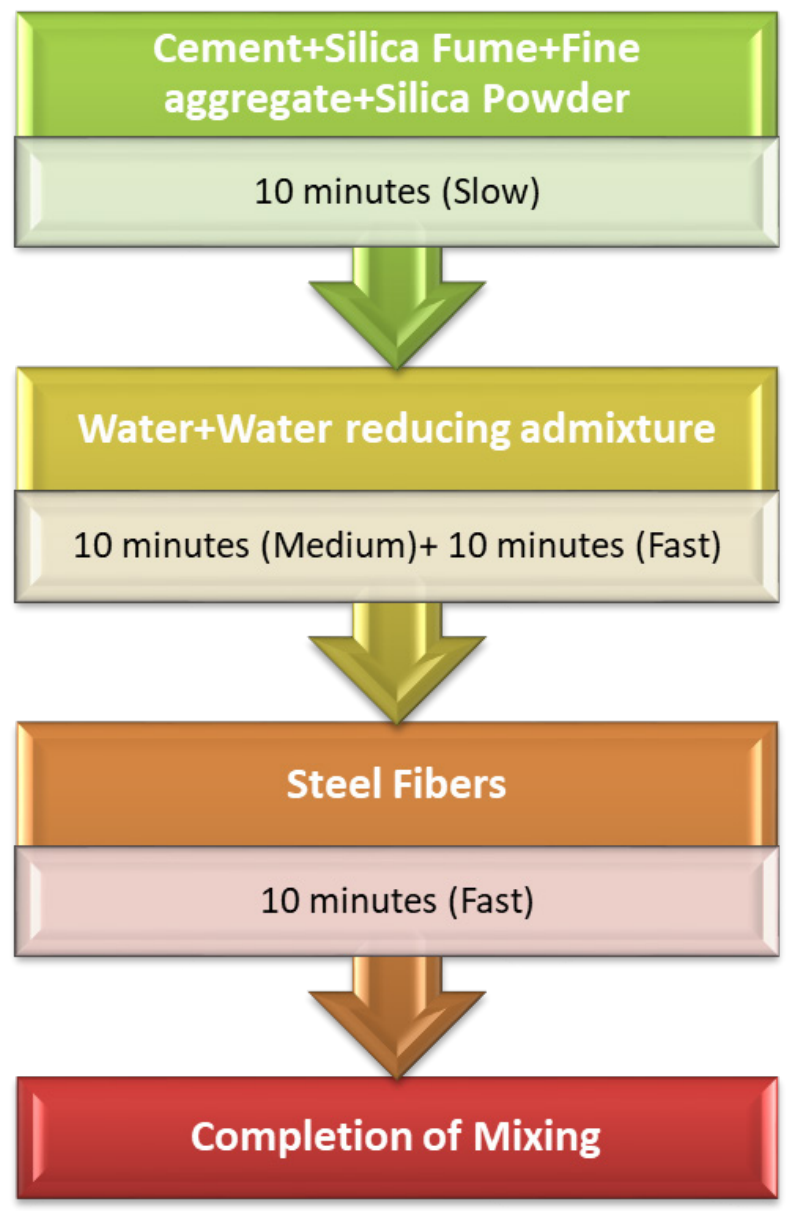

Figure 2. Mixing procedure of UHPFRC 


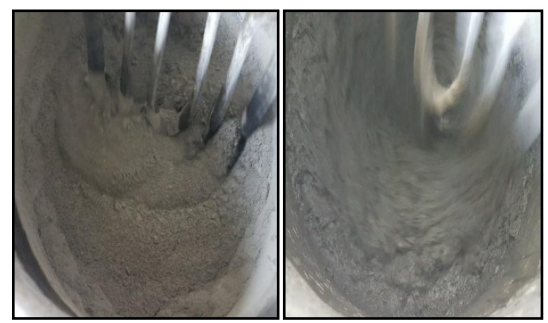

a

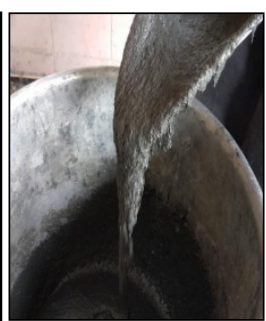

Figure 3. Mixing stages of UHPFRC - (a) Dry mixing of dry ingredients; (b) Wet mixing before fiber addition; (c) Final mix after fiber addition of required consistency

\subsection{Preparation and testing of composite samples of normal concrete substrate and UHPFRC overlay}

The last and the very important phase was the preparation of the composite samples, composed of the normal concrete as the substrate, repaired with a UHPFRC overlay of different thicknesses. The casting process of composite took place in two different phases in two different time periods.

\subsubsection{Casting of the substrate specimens with normal concrete}

Firstly, the casting of the substrate concrete composed of normal concrete was done. The casting process was the same as that followed for the full specimens as mentioned in 2.1. After 24 hours, all of the substrate beams/ slabs were demoulded and cured till the testing date.

\subsubsection{Casting of the UHPFRC overlay}

Almost after one year after the casting of the substrate specimens, the overlay with UHPFRC was placed on the substrate. The reason behind the long pause was to make sure that the substrate concrete has become old enough to overlay with the UHPFRC repair material, to reflect the real-time scenario. The very first step before overlaying the UHPFRC repair material on the substrate beam/ slab specimens was surface preparation, which is one of the key factors, having a significant impact on the bond integrity of the substrate and the overlay. This step involves preparing the surface of the substrate concrete good enough to have an intact bonding with the overlaying material.

With reference to various research studies carried out on preparing the surface of the substrate and laying of the repair material, certain techniques which were considered to be the successful and efficient ones have been transfixed for this study. Therefore, the surface preparation methods such as removal of the top surface of the substrate concrete, roughening, and moistening the substrate surface were adopted in this study to obtain a good interlocking and a better bonding between the concrete of the substrate and the concrete of the overlay. The surface preparation process of and laying of the UHPFRC overlay is explained in the further subsections.

\subsubsection{Surface preparation - Removal of the top surface of} substrate concrete

When preparing the substrate normal concrete slabs/ beams for the repair using UHPFRC overlay, the thickness of the substrate concrete with respect to the thickness of the overlay had to be taken utmost care, since the important objective of the study was the optimization of the overlay thickness. In actual practice, the process of removing the deteriorated concrete from the top layer of the beam/ slab before the application of the overlay was done.

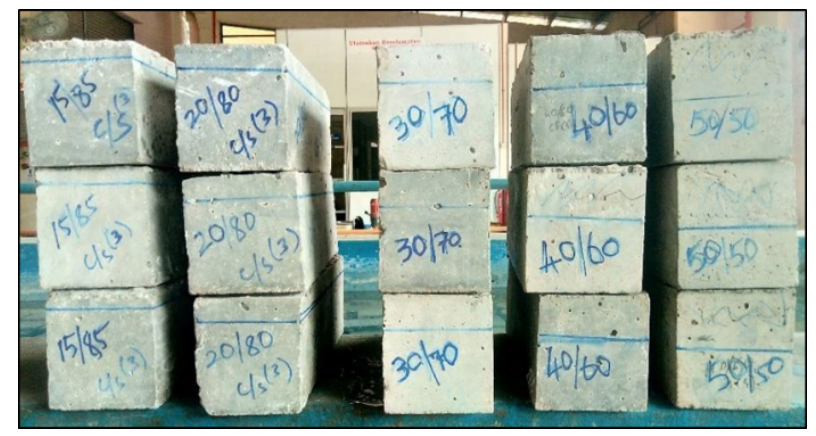

Figure 4. Normal concrete substrate beam specimens measured and marked for the removal of the top surface

In this regard, the top layer of the beams/ slabs was removed according to the required thickness to match with the actual process. Accordingly, the topmost layer of the specimens was measured and marked according to the thickness of the overlay, which had to be replaced with UHPFRC, as shown in Figure 4. Then, the marked topmost layer of the slabs/beams was carefully removed by cutting according to the required thickness of the substrate, as shown in Figure 5, after which the surface roughening was carried out.

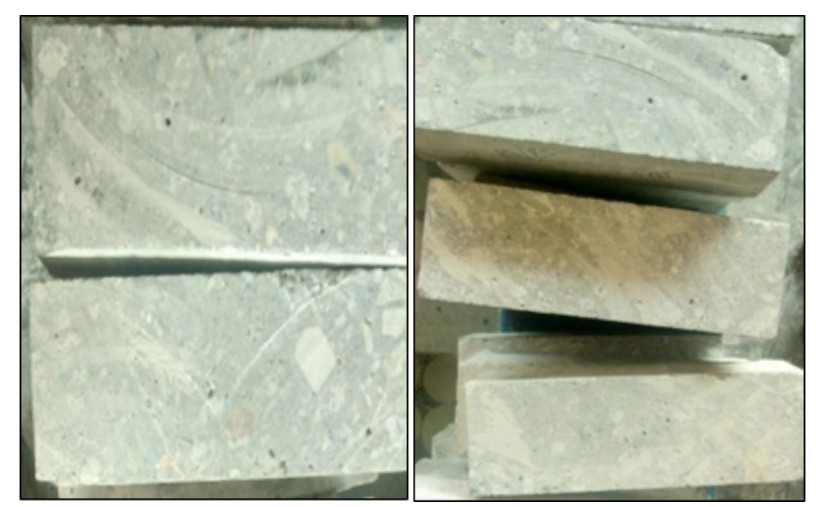

Figure 5. Normal concrete substrate slab and beam specimens after removal of the top surface by cutting

\subsubsection{Surface preparation - Surface roughening by sandblasting}

The effects of surface roughness are mechanical interlocking and contact between substrate concrete and the material used for repair. The geometric profile of the interface increases the contact on the surface area between 
the two types of concretes and enhances the adhesion in the repair system. The strength of the bonding, as well as the physical and chemical properties of the repair material and the concrete substrate, are all affected by the environment [26]. Also, the application of bonding agents should be avoided because it can contribute to the presence of different chemical substances that cannot be substituted as a good adhesion. The development of microstructure and mechanical properties at the interface between two layers of concrete helps to increase the bond strength as stated [27].

Many researchers around the world had tried different types of surface roughening techniques, which are compared to find out the best one which can give the best bonding value. In this regard, a study was conducted to assess the bond strength between two concrete layers of varying ages, taking into account several combinations of added concrete of varying strengths [28]. The effect of substrate roughness on bond strength between concrete and concrete was investigated, and it was discovered that sandblasting achieved the highest bond strength while pre-wetting the substrate surface had no effect on bond strength. According to tests, increasing the compressive strength of the additional concrete relative to the compressive strength of the substrate concrete improves bond strength and shifts the rupture mode from adhesive to monolithic.

Similarly, five different types of surface treatments were evaluated, since the surface roughness has an effect on the bonding strength between normal concrete substrate and the UHPFC as a repair material. Sandblasting surface treatment obtains the highest bonding values followed by grooving surface, wire brush, drill holes, and as-cast surface treatment [15].

There are several techniques for surface roughening, but the one by sandblasting was concluded to be the effective one concerning the findings by one of our previous researchers [15]. In these findings, sandblasting surface treatment obtained the highest bonding values followed by grooving surface, wire brush, drill holes, and as-cast surface treatment, respectively. The surface preparation was done at the factory located in the area of Simpang Ampat Tasik, Pulau Pinang. This procedure aimed to remove the weak concrete layer on top of the normal concrete surface.

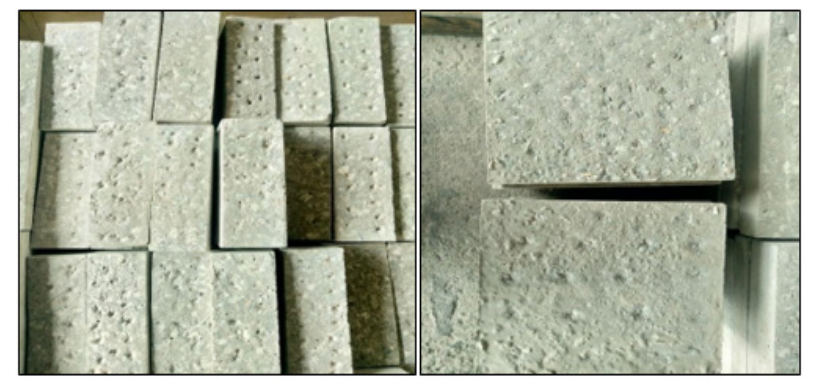

Figure 6. Normal concrete substrate slab and beam specimens after surface roughening by sandblasting
The substrate surface made of normal concrete was sandblasted as a surface roughening treatment, which is done using the dry natural river sand as the main agent with $1000 \mathrm{KPa}$ air pressure to blast the concrete surface, according to the standard that was produced by the ACI Concrete Repair Guide 546R (2014). The samples of beams/ slabs after sandblasting have been shown in Figure 6.

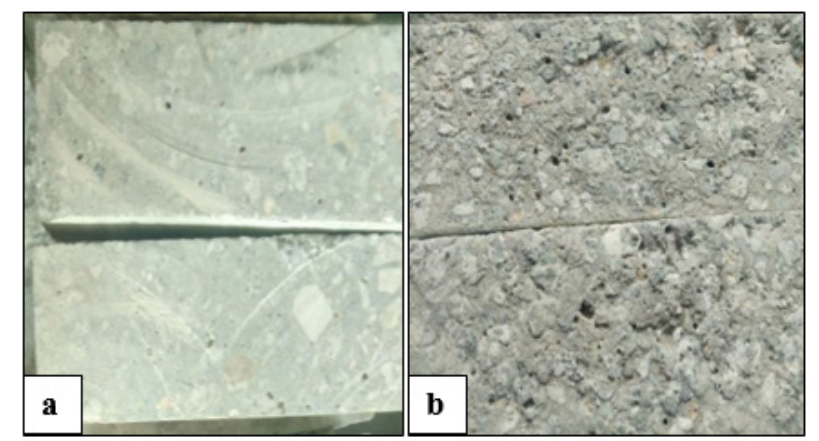

Figure 7. Normal concrete substrate slab specimens before sandblasting (a) and after sandblasting (b)

The surface treatment with sandblasting gives a rough surface with several indentations, which will increase the bonding ability of the overlaid UHPFRC concrete. The transmission of the substrate surface before and after carrying out the surface preparation works has been depicted in Figure 7.

\subsubsection{Application of UHPFRC overlay}

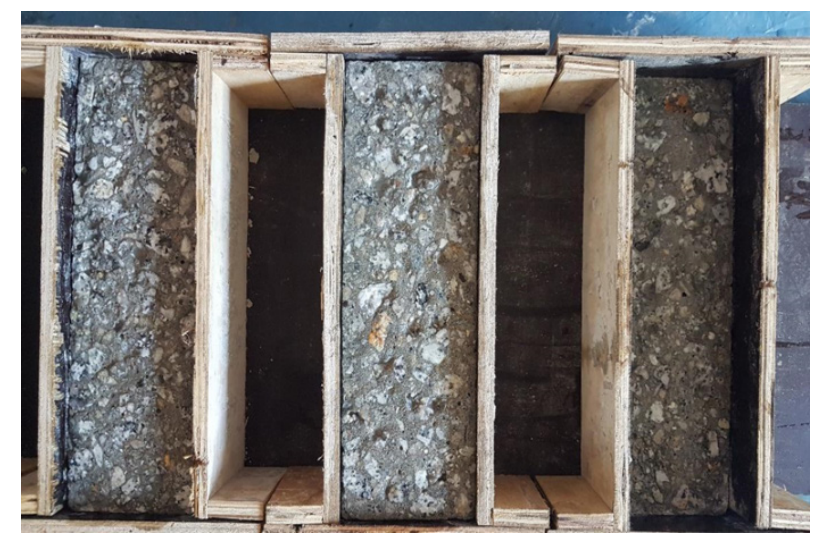

Figure 8. Normal concrete substrate beams specimens, placed inside the moulds for laying UHPFRC overlay, after surface preparation

The next step followed by the completion of the surface preparation process was to overlay the UHPFRC, with regard to the specified thickness. Quite a lot of moulds were fabricated exclusively for the casting of the UHPFRC overlay. The thickness of the UHPFRC overlay ranged from $15 \mathrm{~mm}$ to $50 \mathrm{~mm}$. Hence, according to the thickness of the overlay, the thickness of the substrate normal concrete had been constrained, with reference to the overall thickness of the slabs and beams. For example, if a composite test specimen were to be cast to assess the compressive strength, with a UHPFRC overlay thickness 
of $15 \mathrm{~mm}$, then the substrate thickness would be $85 \mathrm{~mm}$, totaling $100 \mathrm{~mm}$, which is the required specimen thickness $(100 \mathrm{~mm} \times 100 \mathrm{~mm}$ x $100 \mathrm{~mm})$. Similarly, the thickness of the substrate keeps varying with respect to the thickness of the UHPFRC overlay according to the standard specimen dimension required for each test.

With utmost care, already cast substrate specimens were placed inside the moulds, whose top surface were removed according to the thickness of the overlay (ranging from $05 \mathrm{~mm}$ to $50 \mathrm{~mm}$ ), and then the surface had been roughened by sandblasting, as shown in Figure 8. It was made sure that the surface is moistened before the application of the UHPFRC overlay since the dried surface of the substrate might absorb the water from the UHPFRC mix, which in turn will affect the performance of the overlaid UHPFRC. Care was taken not to moisten the surface too much, since it will also affect the performance of UHPFRC.

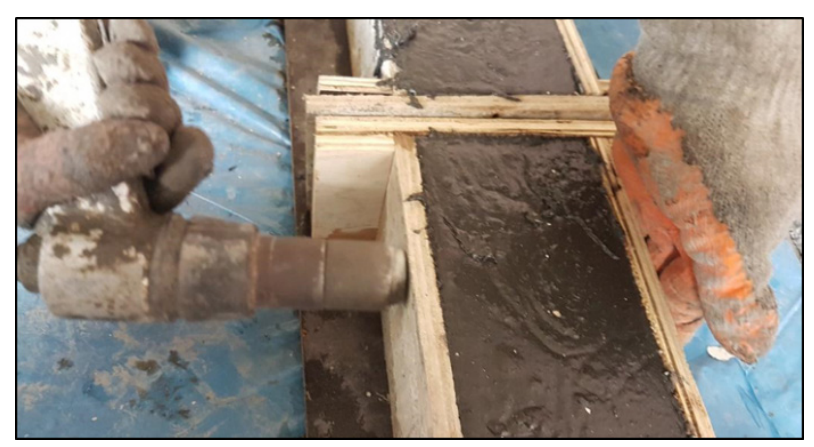

Figure 9. Composite beam specimens subjected to external form vibration, after casting of UHPFRC overlay

All the substrate specimens of normal concrete planned for overlaying in that particular slot had to be kept ready in the moulds with the surface preparation works very well before the mixing of the UHPFRC. Once the mixing of UHPFRC was done, the substrate specimens of different thicknesses were overlaid with freshly mixed UHPFRC. Though the UHPFRC had very good workability, it was very much necessary to do vibration for proper compaction of the laid concrete and a good bond with the substrate concrete. The best method of vibration of the composite specimen composed of old normal concrete substrate and fresh UHPFRC overlay was found to be with an external form vibrator which is presented in Figure 9. The top surface of the specimens overlaid with UHPFRC was appropriately levelled in order to achieve a flattened top surface. After 24 hours, the demolded specimens were subjected to curing as indicated in Figure 10.

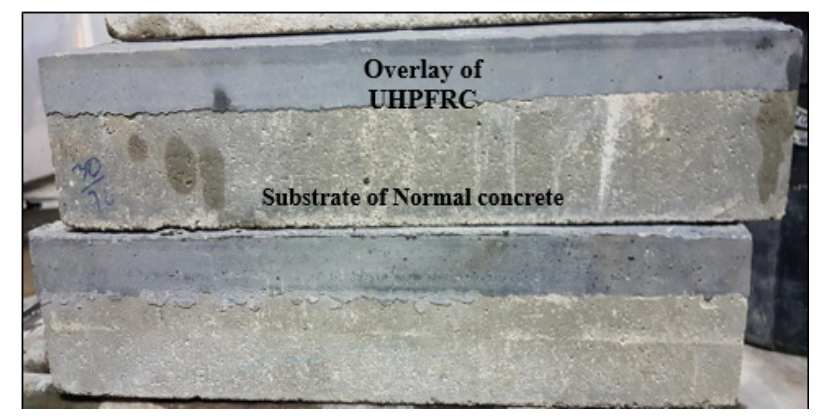

Figure 10. Composite beam specimens cast with the substrate of normal concrete and overlay of UHPFRC

\section{Results and Discussions}

The characterization studies were carried out on the substrate normal concrete and the overlay UHPFRC, as individual concrete types. Also, the behavior of the composite with different thicknesses of the overlay was assessed in compression, tension, and shear as well. The optimum thickness of the UHPFRC repair overlay was determined by comparing the behavior of the composite with the repair overlay thickness with which the original strength of the parent normal substrate concrete could be regained.

\subsection{Basic Mechanical Properties of Substrate Normal Concrete}

The basic mechanical properties such as the compressive strength, flexural strength, slant shear strength, and the split tensile strength of the parent normal concrete used as the substrate for the composite samples were evaluated at the age of 3 days, 7 days 14 days, 28 days and 1 year, and are presented in Table 4.

Table 4. Basic properties of normal concrete used as the substrate for the composite

\begin{tabular}{|c|c|c|c|c|c|}
\hline Properties $\left(\mathrm{N} / \mathrm{mm}^{2}\right)$ & 3 days & 7 days & 14 days & 28 days & 49 \\
\hline Compressive strength & 25 & 38 & 23.66 & 26.89 \\
\hline Slant shear strength & 15.97 & 20.30 & 3.98 & 5.04 \\
\hline Flexural strength & 2.74 & 3.43 & 2.82 & 3.73 & 3.51 \\
\hline Split tensile strength & 1.89 & 2.17 & 3.82 \\
\hline
\end{tabular}




\subsection{Basic Mechanical Properties of UHPFRC}

The basic mechanical properties of the UHPFRC, which were used as the repair overlay material for the composite samples, were also assessed at 28 days, similar to the normal concrete, as is shown in Table 5.

Table 5. Basic properties of UHPFRC

\begin{tabular}{|c|c|}
\hline Properties, $\left(\mathrm{N} / \mathrm{mm}^{2}\right)$ & 28 days \\
\hline Compressive Strength & 156 \\
\hline Slant shear strength & 77 \\
\hline Flexural strength & 20.11 \\
\hline Split tensile strength & 12.90 \\
\hline
\end{tabular}

\subsection{Mechanical Properties of the Composite, Composed of Normal Concrete Substrate and UHPFRC Overlay}

The composite specimens composed of normal concrete as the substrate and the UHPFRC as the overlay was prepared with utmost care as described in the sub-section 2.3., which was a very challenging task of this study. All the composite samples were tailored down to the required sizes for undertaking the property evaluation. The total size of the specimen sample was kept constant according to the sample required for the specific test, but the overlay was varied from $15 \mathrm{~mm}$ to $50 \mathrm{~mm}$ and accordingly the substrate. The varying thickness of the overlay was to identify the optimum thickness requirement of the repair of UHPFRC concrete, with regard to its efficiency. The efficiency was measured based on the mechanical properties of the composite sample. The mechanical properties assessed were compressive strength, flexural strength, split tensile strength, and slant shear strength.

The composites were made of normal concrete as substrate and UHPFRC as an overlay repair concrete. The thickness of the UHPFRC varied between $15 \mathrm{~mm}$ to $50 \mathrm{~mm}$.
Five different thicknesses of UHPFRC overlay such as $15 \mathrm{~mm}, 20 \mathrm{~mm}, 30 \mathrm{~mm} 40 \mathrm{~mm}$, and $50 \mathrm{~mm}$ were employed to assess the optimum thickness for efficiency. The tests were carried out at the end of 28 days and at least three specimens were tested and the average value was taken as the representative value of its compressive strength. All the specimens were first subjected to normal moist curing soon after demolding.

\subsubsection{Compressive strength Vs. Overlay thickness of the composite}

The compressive strength test of the composites was assessed using cubes of $100 \times 100 \times 100 \mathrm{~mm}$. The compressive strength test results of the composite specimens with different overlay thicknesses are demonstrated in Table 6. The failure of the composite specimens had taken place only due to the crushing of the substrate normal concrete and the UHPFRC overlay has been found to be extremely durable. Moreover, the bond between the substrate and the overlay has not shown any failure and the bond remained intact even after the failure.

The compressive strength steadily increased with an increase in the thickness of the overlay, as presented in Figure 11. The compressive strength of a $15 \mathrm{~mm}$ thick UHPFRC overlay with normal curing was found to be 31 $\mathrm{MPa}$ and increased to $59 \mathrm{MPa}$ for an increased UHPFRC overlay thickness of $50 \mathrm{~mm}$. The compressive strength of a full normal concrete specimen at 1 year (just before the application of the UHPFRC overlay) under normal curing is $52 \mathrm{MPa}$, as tabulated in Table 4. After restoration with UHPFRC overlay, the same strength had been re-gained by an overlay thickness between $40 \mathrm{~mm}$ to $50 \mathrm{~mm}$, which is clear from Figure 11. This implies that the original strength of the normal concrete at 28 days under compression can be easily restored under normal curing with an overlay thickness of $40 \mathrm{~mm}$.

Table 6. Compressive strength of composites with varying thickness of UHPFRC overlay

\begin{tabular}{|c|c|c|c|c|c|}
\hline Thickness of UHPFRC overlay $(\mathrm{mm})$ & 15 & 20 & 30 & 40 \\
\hline Compressive strength $\left(\mathrm{N} / \mathrm{mm}^{2}\right)$ & 31 & 36 & 41 & 47 \\
\hline
\end{tabular}

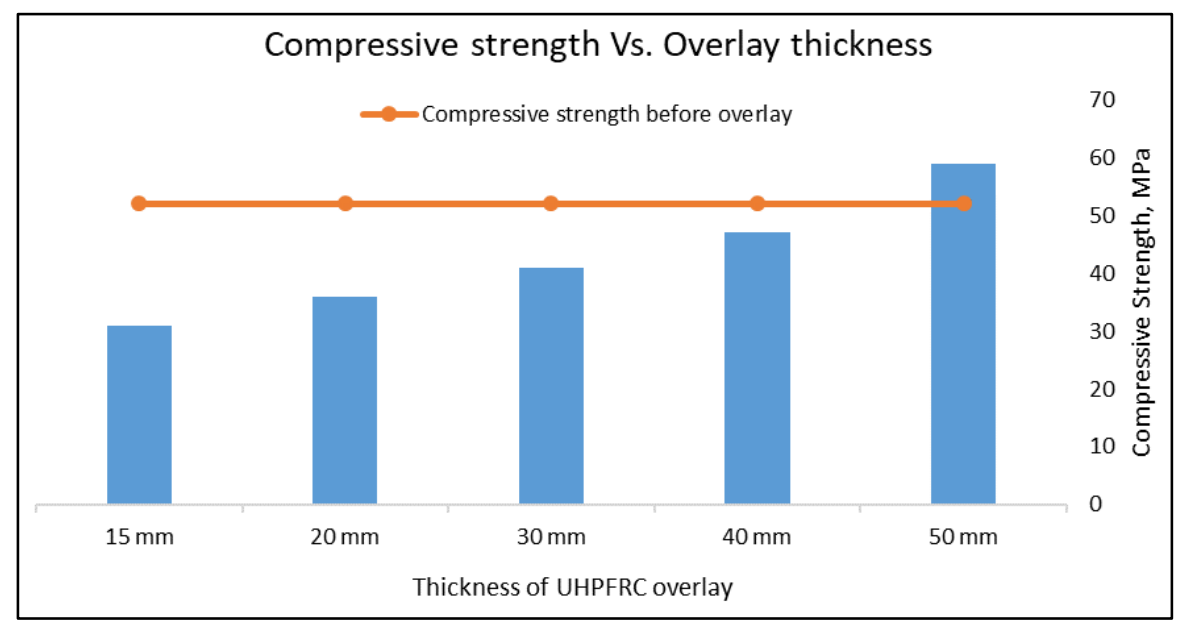

Figure 11. Compressive strength Vs. Overlay thickness of UHPFRC 
With the above outcomes of the compressive strength results of the composite specimens with overlay thickness ranging from $15 \mathrm{~mm}$ to $50 \mathrm{~mm}$, it is obvious that the optimum thickness of the overlay to restore the original strength is $40 \mathrm{~mm}$ in compression.

\subsubsection{Flexural strength Vs. Overlay thickness of the composite}

Beams of size $500 \times 100 \times 100 \mathrm{~mm}$ were used to evaluate the flexural strength of the composites. The beams were laid with their overlay at the bottom side, during the conduct of the test, in order to get the effectiveness of the overlay in the flexural strength results. The flexural strength test results of the composite specimens with different overlay thicknesses are demonstrated in Table 8. The beam is placed in such a way that the UHPFRC overlay applied is subjected to flexure when subjected to the test. Also, the failed face of the beam evidently indicates that the failure of the overlay in the composite has happened due to the pull out of concrete from fibers and still the fibers remained intact.

The flexural strength steadily increased with an increase in the thickness of the overlay, as shown in Table 7. The flexural strength of a $15 \mathrm{~mm}$ thick UHPFRC overlay with normal curing was found to be $9.20 \mathrm{MPa}$, and with an increase in the thickness of the overlay, the flexural strength increased to $20.02 \mathrm{MPa}$. This scenario is the same as that of the compressive strength behaviour of the composite, which is as discussed in the previous section.

The flexural strength of a full normal concrete specimen at 1 year (just before the application of the UHPFRC overlay) under normal curing is $5.5 \mathrm{MPa}$, as tabulated in Table 4. After restoration with UHPFRC overlay, for a minimum overlay thickness of $15 \mathrm{~mm}$, the lowest strength achieved was $9.20 \mathrm{MPa}$, which is almost twice that of a full normal concrete specimen. On the other hand, the flexural strength of a full UHPFRC specimen at 28 days is $20.11 \mathrm{MPa}$, as given in Table 5, which is more than double times the value of a $15 \mathrm{~mm}$ overlay strengthened beam. A similar value of flexural strength achieved by a full UHPFRC beam specimen has been achieved by a restored beam having an overlay thickness of $50 \mathrm{~mm}$, which is $20.02 \mathrm{MPa}$. This behavior is directly related to the percentage of UHPFRC material present in the beam and the portion of the beam under flexure. The strengthened beam with a $50 \mathrm{~mm}$ UHPFRC overlay behaves the same way as that of a full UHPFRC beam in flexure since the portion of the beam under flexure is the same in both cases.

The restored beam of a minimum overlay thickness of $15 \mathrm{~mm}$ UHPFRC itself achieved a double times increase in flexural strength value of 9.20 MPa when compared to the flexural strength of a normal beam, which was 5.5 $\mathrm{MPa}$, which is evident from Figure 12. Hence, a minimum thickness of the UHPFRC overlay would be sufficient to restore a normal concrete beam. The flexural strength of a full UHPFRC beam at 28 days is very much similar to that of a restored beam of $50 \mathrm{~mm}$ overlay since the portion of the beam under flexure is the same. Hence, a beam restored with $50 \%$ of the repair overlay material can be expected to behave in flexure, the same way as that of a full UHPFRC beam. Hence, the performance of the restored beam with a minimum overlay thickness of 15 $\mathrm{mm}$ would be superior enough for repair.

Table 7. Flexural strength of composites with varying thickness of UHPFRC overlay

\begin{tabular}{|c|c|c|c|c|c|}
\hline Thickness of UHPFRC overlay $(\mathrm{mm})$ & 15 & 20 & 30 & 40 & 50 \\
\hline Flexural strength $\left(\mathrm{N} / \mathrm{mm}^{2}\right)$ & 9.20 & 10.20 & 15.14 & 18.59 & 20.02 \\
\hline
\end{tabular}

Flexural strength Vs. Overlay thickness

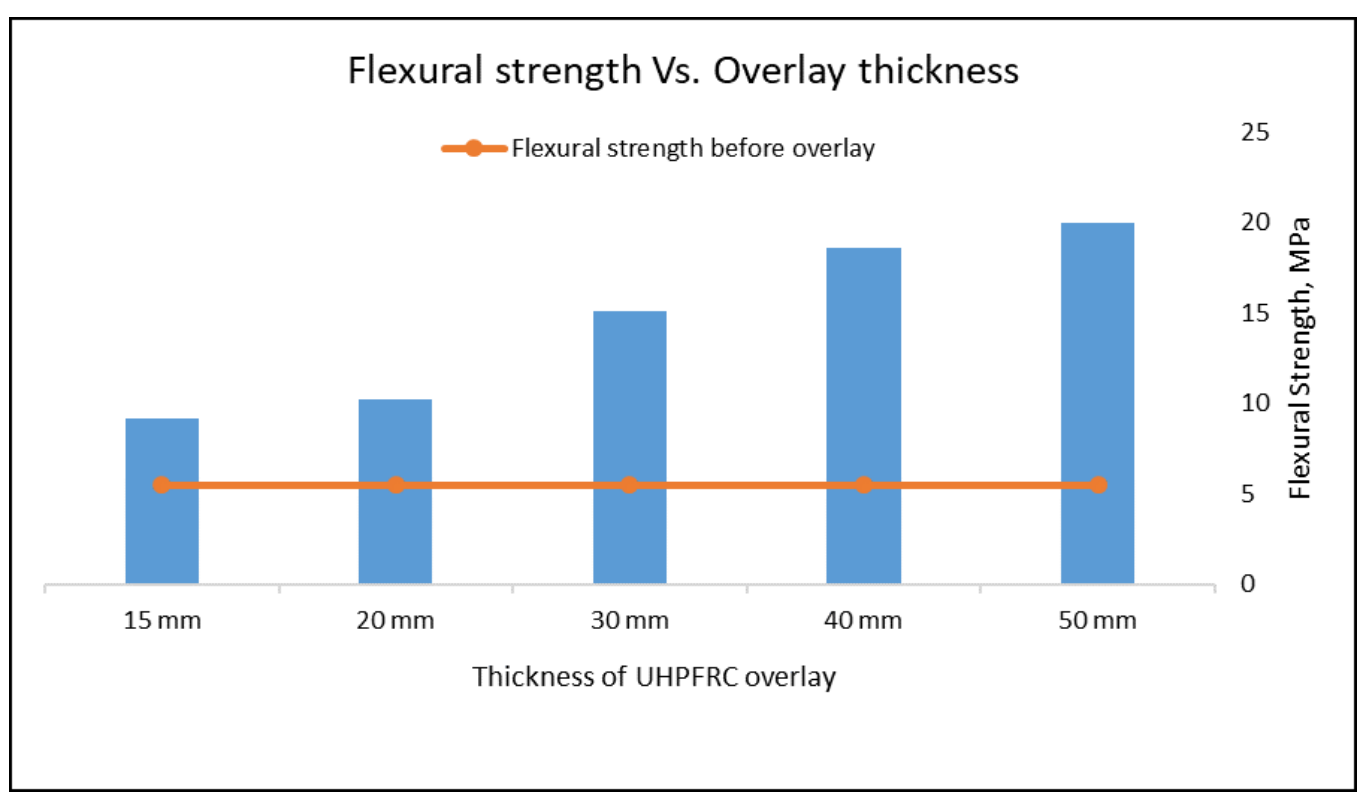

Figure 12. Flexural strength Vs. Overlay thickness of UHPFRC 
Table 8. Split tensile strength of composites with varying thickness of UHPFRC overlay

\begin{tabular}{|c|c|c|c|c|c|}
\hline Thickness of UHPFRC overlay $(\mathrm{mm})$ & 15 & 20 & 30 & 40 & 50 \\
\hline Split tensile strength $\left(\mathrm{N} / \mathrm{mm}^{2}\right)$ & 4.59 & 5.48 & 7.13 & 7.52 & 8.79 \\
\hline
\end{tabular}

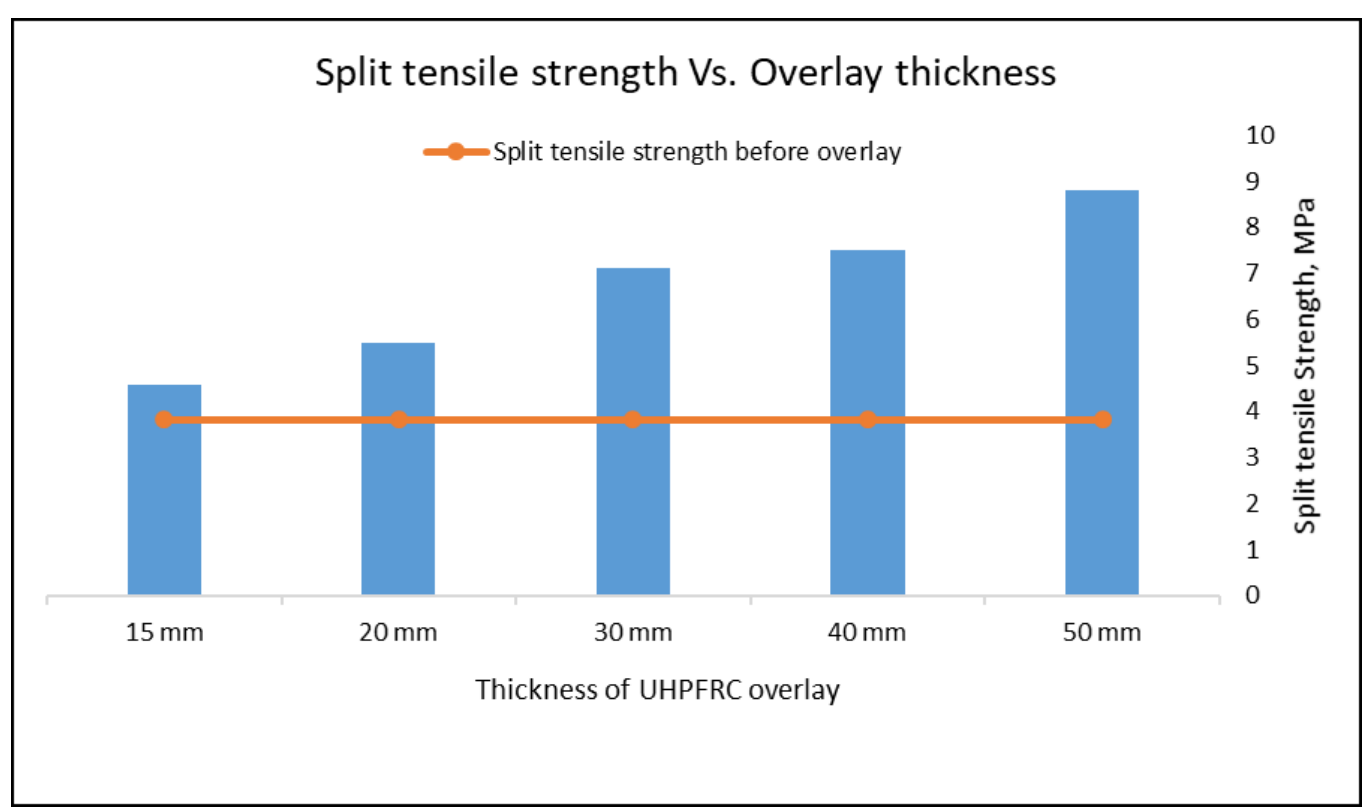

Figure 13. Split tensile strength Vs. Overlay thickness of UHPFRC

\subsubsection{Split tensile strength Vs. Overlay thickness of the} composite

Cylinders of $100 \mathrm{~mm}$ diameter and $200 \mathrm{~mm}$ height were used to evaluate the split tensile strength of the composite samples. The composite specimens repaired with UHPFRC overlay with varying thicknesses ranging from $15 \mathrm{~mm}$ to $50 \mathrm{~mm}$ were evaluated for their split tensile strength. The split tensile strength steadily increased with an increase in the thickness of the overlay, as shown in Table 9.

The trend towards the increasing in the split tensile strength from $15 \mathrm{~mm}$ to $50 \mathrm{~mm}$ was similar to that of the compressive strength and the flexural strength. The split tensile strength of a $15 \mathrm{~mm}$ thick UHPFRC overlay with normal moist curing was found to be $4.59 \mathrm{MPa}$, which increased to $8.79 \mathrm{MPa}$ for an increased overlay thickness of $50 \mathrm{~mm}$.

The split tensile strength of a full normal concrete specimen at 1 year (just before the application of the UHPFRC overlay) under normal curing is $3.82 \mathrm{MPa}$, as tabulated in Table 4. After restoration with UHPFRC overlay, for a minimum overlay thickness of $15 \mathrm{~mm}$, the minimum strength achieved was $4.59 \mathrm{MPa}$, given in Table 9, which is even higher than that of the original full normal concrete specimen. Likewise, for a maximum overlay thickness of $50 \mathrm{~mm}$, the maximum split tensile strength attained was $8.79 \mathrm{MPa}$. On the other hand, the split tensile strength of a full UHPFRC specimen at 28 days is $12.9 \mathrm{MPa}$, given in Table 5, which clearly depicts that the composite repaired with $50 \mathrm{~mm}$ UHPFRC overlay gains a split tensile strength, almost $3 / 4$ th of a full
UHPFRC specimen. Hence, a minimum thickness of 15 $\mathrm{mm}$ UHPFRC overlay is more than sufficient to repair and restore a normal concrete beam, which behaves, even more, better than the normal concrete specimen, in terms of split tensile strength.

The restored beam of a minimum overlay thickness of $15 \mathrm{~mm}$ UHPFRC itself achieved a higher value of split tensile strength 4.59 $\mathrm{MPa}$ when compared to the split tensile strength of a normal concrete beam, which was only 3.82 MPa, is clearly evident from Figure 13. Hence, a minimum thickness of $15 \mathrm{~mm}$ UHPFRC overlay would be sufficient to restore a normal concrete beam. The split tensile strength of a $50 \mathrm{~mm}$ UHPFRC overlay, was 8.79 $\mathrm{MPa}$, which is almost $3 / 4$ th of a full UHPFRC specimen that has attained a split tensile strength of $12.9 \mathrm{MPa}$. Hence, the performance of a composite beam restored with the maximum overlay thickness of $50 \mathrm{~mm}$ can be expected to behave almost like a UHPFRC beam itself. Hence, the performance of the restored beam with a minimum overlay thickness of $15 \mathrm{~mm}$ with UHPFRC would be enough for repair to restore the original strength of the normal concrete beam.

\section{Conclusions}

The performance of the composite after restoring with different thicknesses ranging from $15 \mathrm{~mm}$ to $50 \mathrm{~mm}$ of the UHPFRC overlay was compared to the original strength restoration of the substrate normal concrete. The thickness optimization of the repair UHPFRC overlay showed good 
outcomes with respect to compression and tension as well. A minimum UHPFRC overlay thickness of $15 \mathrm{~mm}$ was more than enough to repair and restore the original strength of the normal concrete, under tension. This minimum thickness of overlay can be very efficient in restoring the strength of the normal concrete slabs which will turn to be more economical due to its minimal consumption. Likewise, an overlay thickness of $40 \mathrm{~mm}$ is sufficient to repair and restore the original strength of the normal concrete under compression. Hence, the overlay thickness can be restricted to $40 \mathrm{~mm}$ in order to restore the original strength of a normal concrete beam and can avoid higher overlay thickness, which can greatly reduce the cost involved in the higher consumption of materials. Furthermore, the maximum UHPFRC overlay thickness of $50 \mathrm{~mm}$ showed a behaviour equal to that of a fully UHPFRC specimen in tension.

\section{REFERENCES}

[1] Naaman A.E. and Wille K, (2012). The Path to Ultra-High Performance Fiber Reinforced Concrete (UHP-FRC) - Five Decades of Progress, Proceedings of Hipermat 2012 - 3rd International Symposium on UHPC and Nanotechnology for Construction Materials"; pp. 3-15.

[2] Resplendino J, (2012). State of the art of design and construction of UHPFRC structures in France, Proceedings of Hipermat 2012 - 3rd International Symposium on UHPC and Nanotechnology for Construction Materials, pp. 27-41.

[3] Habel, K., Viviani, M., Denarié, E. and Brühwiler, E., (2006). Development of the mechanical properties of an ultra-high performance fiber reinforced concrete (UHPFRC). Cement and Concrete Research, 36(7), pp.1362-1370.

[4] Russell, H.G., Graybeal, B.A. and Russell, H.G., (2013). Ultra-high performance concrete: a state-of-the-art report for the bridge community (No. FHWA-HRT-13-060). The United States. Federal Highway Administration. Office of Infrastructure Research and Development.

[5] Alaee and Karihaloo, (2003). Retrofitting of Reinforced Concrete Beams with CARDIFRC, Journal of Composites for Construction, Vol. 7, Issue 3.

[6] Graybeal, B.A., (2006). Material property characterization of ultra-high performance concrete (No. FHWA-HRT-06-103). The United States. Federal Highway. Office of Infrastructure Research and Development.

[7] Habel, K., Viviani, M., Denarié, E. and Brühwiler, E., (2006). Development of the mechanical properties of an ultra-high performance fiber reinforced concrete (UHPFRC). Cement and Concrete Research, 36(7), pp.1362-1370.

[8] Chong Wang, Changhui Yang, Fang Liu, Chaojun Wan and Xincheng $\mathrm{Pu}$, (2012). Preparation of Ultra high performance concrete with common technology and materials, Cement \& Concrete research, Vol. 34, pp.
$538-544$.

[9] Barros J. A. O and Figueiras JA, (1999). Flexural behaviour of SFRC: testing and modelling, Journal of materials of civil engineering, Vol. 11(4), pp. 331-339.

[10] Yang, J., Yoo, D., Kim, Y. and Yoon, Y. (2017). Mechanical Properties of Steam Cured High-Strength Steel Fiber-Reinforced Concrete with High-Volume Blast Furnace Slag, International Journal of Concrete Structures and Materials. Springer Netherlands, 11(2), pp. 391-401.

[11] Murali, G., Venkatesh, J., Lokesh, N. et al. Comparative Experimental and Analytical Modeling of Impact Energy Dissipation of Ultra-High Performance Fibre Reinforced Concrete. KSCE J Civ Eng 22, 3112-3119 (2018).

[12] Habel, K., Viviani, M., Denarié, E. and Brühwiler, E., (2006). Development of the mechanical properties of an ultra-high performance fiber reinforced concrete (UHPFRC). Cement and Concrete Research, 36(7), pp.1362-1370.

[13] Nguyen, DL., Tran, VT., Tran, NT. et al. Evaluating Load-Carrying Capacity of Short Composite Beam Using Strain-Hardening HPFRC. KSCE J Civ Eng 25, 1410-1423 (2021).

[14] Qurania T. Tsioulou, Andreas P. Hampropoulous and Stephanos E. dritsos, (2013). Experimental investigation of interface behavior of RC beams strengthened with concrete layers, Construction \& Building materials, Vol. 40, pp. 50-59.

[15] Guan, Y., Wu, J., Sun, R. et al. Transverse Flexural Behaviour of Steel-Engineering Cementitious Composites (ECC) Composite Deck under Negative and Positive Bending Forces. KSCE J Civ Eng (2021).

[16] Tayeh, B. A., Abu Bakar, B. H., Megat Johari, M. A. and Voo, Y. L. (2012). Mechanical and permeability properties of the interface between normal concrete substrate and ultra-high performance fiber concrete overlay, Construction and Building Materials. 36, pp. 538-548.

[17] Tayeh, B. A., Abu Bakar, B. H., Megat Johari, M. A. and Voo, Y. L. (2013) Utilization of ultra-high performance fibre concrete (UHPFC) for rehabilitation a review, Procedia Engineering, 54, pp. 525-538.

[18] Tayeh, B. A., Abu Bakar, B. H., Megat Johari, M. A. and Voo, Y. L. (2013) Evaluation of bond strength between normal concrete substrate and ultra-high performance fiber concrete as a repair material, Procedia Engineering, 54, pp. 554-563.

[19] Sarah V. Shann, (2012). Application of Ultra High Performance Concrete (UHPC) as a thin-bonded overlay for concrete bridge decks"; Thesis - Virginia Polytechnic Institute \& State University.

[20] AFGC: Interim recommendations: UHPFRC (2002).

[21] Cheyrezy M, Maret V and Frouin L, (1995). Microstructural analysis of reactive powder concrete, Cement and concrete research, Vol. 25(7), pp. 1491-1500.

[22] Dallaire E, Aitcin P C and Lachemi M 1998 High performance powder. CE-ASCE 68(1): 48-51

[23] Dili A S and Santhanam M 2004 Investigation on RPC: a 
developing ultra-high-strength technology. ICJ 4: 33-38

[24] Graybeal, B. and Tanesi, J., (2007). Durability of an ultrahigh-performance concrete. Journal of materials in civil engineering, 19(10), pp.848-854.

[25] Prabhat R. P., Bharatkumar and Nagesh R Iyer, (2013). Influence of curing regimes on compressive strength of ultra-high performance concrete, Sadhana - Indian academy of sciences, Vol. 38 (6), pp. 1421-1431.

[26] A. Garbacz, M. Górka, L. Courard, (2005). On the effect of concrete surface treatment on adhesion in repair systems, Mag. Concr. Res. 57 (2005) 49-60.

[27] L. Courard, T. Piotrowski, A. Garbacz, (2014). Near-to-surface properties affecting bond strength in concrete repair, Cem. Concr. Comp. 46.

[28] Ealuardo N. B. S. Julio, Fernando A. B. Branco, and Vitor D. Silva, (2004). Concrete to concrete bond strength; Influence of the roughness of the substrate surface, Construction \& Building materials, Vol. 18, pp. 675-681. 